\title{
MULTI-MODELO DE REFERÊNCIA PARA DEFINIÇÃO DE ESTRATÉGIAS EM ESPECTRO DE ALTA COMPLEXIDADE
}

\section{MULTI-MODEL REFERENCE FOR THE DEFINITION OF HIGHLY COMPLEX SPECTRUM OF STRATEGIES}

\author{
Selma Regina Martins Oliveira ${ }^{1}$; Edson Walmir Cazarini ${ }^{2}$ \\ ${ }^{1}$ Universidade de São Paulo/USP - EESC - São Carlos - Brasil \\ selmaregina@webmail.uft.edu.br \\ ${ }^{2}$ Universidade de São Paulo/USP - EESC - São Carlos - Brasil \\ selmaregina@webmail.uft.edu.br
}

\begin{abstract}
Resumo
Este artigo tem por propósito contribuir para uma política de planejamento no campo da educação a distância (EAD). Para isto concebe uma proposta multi-modelo de referência lastreada na definição de estratégias em espectro de alta complexidade, que considera uma seqüência de procedimentos sistematizados nas seguintes fases: (i) determinação das necessidades de informação, em duas etapas: (a) identificação dos fatores críticos de sucesso (FCS) e (b) identificação das áreas de informação; (ii) determinação das competências; (iii) determinação dos graus de avaliação de competências; (iv) determinação das estratégias em redes de conhecimentos. Evidencia-se a aplicação a um estudo de caso nas concessões rodoviárias no Brasil, na perspectiva das parcerias público-privadas (PPPs). A consecução da pesquisa foi por meio da intervenção de especialistas e um grupo pequeno de estudantes de um programa de EAD (MBA) aplicado às PPPs. Vários instrumentos de apoio foram utilizados na elaboração da modelagem, com vistas a reduzir a subjetividade nos resultados alcançados: escalagem psicométrica - Lei dos Julgamentos Categóricos de Thurstone (LJC), Multicriteriais-Compromise Programinng, Electre III, $e$ Promethee II; Análise Multivariada; Redes Neurais Artificiais (RNA); Redes Neurofuzzy. Os resultados produzidos mostraram-se satisfatórios, validando o procedimento proposto para EAD.
\end{abstract}

Palavras-Chave: educação a distância; planejamento; multi-modelo de referência; parcerias público-privadas (PPPs).

\section{Introdução}

Recentemente o desenvolvimento de competências pessoais deixou de ser uma decisão pessoal e passou a ser estratégia das empresas. Respostas vêm sendo dadas a esses desafios. Apesar de ainda isoladas, certas proposições começam a ser incorporadas no meio acadêmico e empresarial, para redirecionar as questões de ensino e aprendizagem. E o fato das pessoas manterem-se atualizadas vem reforçar a importância da Educação a Distância (EAD) na formação continuada, reinserindo os indivíduos em novas sociedades construídas em torno da informação e 
do saber e colocando-a como uma das "mais notáveis" manifestação da mundialização (ATKINSON, 1991; LABAY; COMM, 2003; LITO; FORMIGA, 2008; MILLER, 1989; MIHHAILOVA, 2006; MOORE; KEARSLEY, 2007; SADLER-SMITH et al., 2000; MOORE, 1993; PETERS, 2001).

O objetivo da EAD é a formação da rede humanizante colaborativa, onde todos os participantes fazem releituras e constróem conhecimentos, inclusive os professores. $\mathrm{O}$ "aprender a aprender" ainda é pouco "digerido" por alguns e a EAD pede por ele o tempo todo. A autonomia, a auto-programação, a motivação são oportunizadas pela interação gerada no ambiente, onde o professor tem papel imprescindível.

O desenrolar de um projeto de EAD envolve uma diversidade de eventos de grande complexidade, num contexto de incerteza e risco, podendo afetar o fluxo do projeto, frustrando expectativas de estabilidade. Há de se ter em mente que os riscos podem advir de diversas origens e cenários, provocados por eventos ambientais ou advindos do próprio projeto. É necessário refletir no sentido de que a implementação de projetos de EAD não será simples e um dos principais focos refere-se à organização dos recursos utilizados para capacitar as pessoas afim de obterem competências necessárias com vistas a uma determinada performance de trabalho (TSINGHUA UNIVERSITY, 2008; UNITED STATES DISTANCE LEARNING ASSOCIATION (USDLA), 2000; UNIVERSIDAD NACIONAL DE EDUACIÓN A DISTANCIA, 2008; UNIVERSITAS TERBUKA; 2008; UNIVERSITY OF SOUTH AFRICA, 2008; UNIVERSITY OF THE AIR, 2008; MOORE; KEARSLEY, 2007; LUZZY, 2007; LITO; FORMIGA, 2008; PAYAME NOOR UNIVERSITY, 2008).

As características dos projetos diferem muito, sendo objeto de análise igualmente diferenciada. Além disso, a literatura ainda diverge no tocante a concepção da EAD. A boa prática recomenda o cumprimento de uma seqüência de ações articuladas, que consiste nas seguintes fases : A fase (i) contempla duas etapas: (1) - (i) planejamento das necessidades; (ii) institucionalização e formação da equipe de projetos e determinação dos procedimentos de comunicação (inclusive teste de mercado) ; (iii) consolidação dos objetivos, resultados e das metas de desempenho do projeto ; (iv) esboço do projeto de referência ; (v) estudo dos custos, receitas, fluxos de caixa ; (vi) estudo dos impactos sociais; (vii) análise, alocação e gestão de riscos (avaliação preliminar) ; e (viii) análise da viabilidade básica. Etapa (2): (i) refinamento do projeto; e (ii) refinamento do estudo de custos, dos impactos, e de riscos. Fase (ii); Desenvolvimento/Implementação; e evolução e continuação (CARVALHO, 2001; KAYE, 1989; LAASER, 1997; LEVY, 2007).

As antigas práticas já não mais se justificam, o que requer desvencilhar-se de valores passados e introduzir efeitos adequados a esse tempo. Compreensão esta que não é seguida tão de perto por quem gerencia EAD. Evidentemente que a crise paradigmática na educação não é fruto da 
EAD, mas sem dúvida a EAD introduz mudanças significativas no campo das práticas educacionais tradicionais e, conseqüentemente, no modelo pedagógico, traduzindo inovações na forma de aprender e ensinar.

De todos esses elementos resulta a atratividade de um projeto de EAD, sobretudo o seu retorno e estabilidade. Muitas vezes os projetos são inviabilizados ainda na fase de planejamento, tornando-os insustentáveis. Um dos pontos que bem merece ser destacados é a ocorrência de erros na implementação dos projetos, que muitas vezes resulta no não cumprimento das metas estabelecidas. A eficiência no planejamento dos projetos propicia a tomada de decisões mais eficazes, diminuindo o improviso e potencializa a equipe envolvida.

É de salientar que a EAD no Brasil ainda é uma tarefa científica mal começada, embora se possa enumerar uma quantidade de títulos já disponíveis sobre o assunto, poucas obras se prestam para a construção sistemática da experiência brasileira no setor. Os métodos e técnicas para viabilizar EAD no Brasil ainda se encontram em situação de desvantagem quando se compara às experiências internacionais: é carente em aportes materiais, tecnológicos e humanos. O conhecimento é insuficiente, e o capital intelectual é despreparado, o que torna insustentável viabilizar projetos tão relevantes. Seja como for, os modelos seguem, de alguma forma, uma lógica racional, embora com muitos acidentes de percurso e erros no detalhe.

Tradicionalmente a fase de planejamento é elaborada sem apoio de métodos e técnicas adequados priorizando realmente aquilo que é essencial na formação de competências profissionais. Configura-se o objetivo deste trabalho que é contribuir para uma política de planejamento no campo da educação a distância (EAD). Para isto concebe uma proposta multi-modelo de referência lastreada na definição de estratégias em espectro de alta complexidade, de maneira integrada.

\section{A Modelagem}

Nesta seção são apresentados os procedimentos para o desenvolvimento da modelagem. A proposta está subdividia em duas fases: construção e verificação da modelagem. A modelagem proposta representa um conjunto de variáveis e procedimentos articulados e ordenados numa tomada de decisão, que tem nos FCS, nas competências e nas estratégias de EAD seus elementos norteadores. Detalha-se a seguir a elaboração do modelo.

\subsection{Suposições teóricas para concepção do modelo}

A estrutura do modelo se orienta em suposições teóricas e está fundamentalmente lastreada nos pressupostos das experiências nacionais e internacionais de EAD (ABELES, 2005; BINSARDI; EKWULUGO, 2003; FREEMAN; THOMAS, 2005; GOMES; MURPHY, 2003; SADLER-SMITH et al., 2000; KING, 1995; MORRISON, 2003; KHAN, 2005; KING, 1995; ALLAMA IQBAL 
OPEN UNIVERSITY, 2008; ICDE. INTERNATIONAL COUNCIL FOR DISTANCE EDUCATION, 2008; LITO; FORMIGA, 2008; MOORE; KEARSLEY, 2007). Sendo assim, são apresentadas as seguintes suposições: (i) a EAD pode ser vista como um problema classificado em espectro de alta complexidade; (ii) as características das falhas dos projetos em EAD devem ser consideradas na concepção dos projetos de EAD; (iii) as características da configuração do ambiente (trabalho, preferências individuais, entre outros) influenciam diretamente as decisões individuais por EAD. A inter-relação altera as decisões individuais que afetam o sistema de EAD; (iv) a análise da demanda por qualificação profissional passou por uma mudança de paradigma principal; (v) a configuração econômica e financeira, política, social e mercadológica; (vi) a formação de competências em um sistema de EAD tem nos FCS a referência pretendida pelos indivíduos (programa de EAD), e por conseguinte influencia na definição e redefinição das estratégias em EAD; (vii) as características culturais influenciam diretamente as estratégias do sistema de EAD; (viii) os condicionantes que motivam os indivíduos a procurarem por programas de EAD não podem ser reduzidos à medidas simples de custo e deslocamento; (ix) A inclusão de variáveis estratégicas altera a significância estatística da modelagem; (x) a redefinição na estrutura da dinâmica das competências; e (xi) a abordagem baseada em competências requer estratégias flexíveis. Uma vez identificadas as suposições teóricas, o passo seguinte é o levantamento dos elementos básicos na concepção do modelo, sistematizados a seguir.

\subsection{Elementos Básicos para a Concepção do Modelo}

Nesta seção é concebido o modelo à luz das seguintes definições:

Padrões de estratégias na rede de conhecimentos: A análise de padrões de estratégias pode ser vista como um problema de classificação em que a entrada é um conjunto de elementos constituintes de estratégias e a saída é a classificação destes elementos dentro de um conjunto de categorias "natural" ou "pré-determinadas". No modelo, os padrões de estratégias (Pe) estarão constituídos de um conjunto de categorias, em que o começo e final da cadeia são pré-determinados ao iniciar o módulo ou programa de EAD e finaliza com o término do programa ou módulo de EAD, que pressupõe à formação de competências. A classificação do padrão (Pe) de estratégias poderá ser representada segundo o propósito do objetivo principal dos participantes do programa ou módulo de EAD.

i.Padrões de competências para definição de estratégias: A análise de padrões de competências pode ser vista como um problema de classificação em que a entrada é um conjunto de competências e a saída é a classificação destas competências dentro de um conjunto de categorias natural ou pré-determinadas. No modelo, os padrões de competências estarão constituídos de um conjunto de categorias, em que o começo e final da cadeia são pré-determinados ao término do 
programa ou módulo de EAD. As competências podem ser classificadas em três grupos: Conhecimentos + Habilidades + Atitudes $(\mathbf{C}+\mathbf{H}+\mathbf{A})$. O “+” representa o acréscimo do tempo de formação das competências.

ii.Padrão de redes de conhecimentos (sistema de EAD): A análise de padrões de redes de conhecimentos pode ser vista como um problema de classificação em que a entrada é um conjunto de medidas que definem um padrão de estratégias de rede de conhecimentos, que resulta do grau de avaliação de competências individuais "ex-ante" e "ex-post" ao programa de capacitação, gerado a partir dos FCS. E a saída resulta o desempenho dessas estratégias dentro de um conjunto de categorias "natural" ou "predeterminada". No modelo, os padrões de redes de conhecimentos estarão constituídos de um conjunto de categorias, em que o começo e final da cadeia são prédetermiandos "ex-ante" e "ex-post" ao programa ou módulo de EAD. O propósito das estratégias pode ser classificado conforme os "conhecimentos + habilidades + atitudes". O "+" representa o acréscimo de pelo menos uma competência adicional em resposta ao impacto das estratégias.

iii.Encadeamento das estratégias: a reprodução e representação do comportamento das estratégias em função do padrão $(\mathbf{R})$.

iv.Características do contexto (C), dos indivíduos (I), as motivações (M) no espaço-tempo: Seja o contexto com suas características econômicas, sociais, políticas, mercado; as pessoas com seus diferentes tipos de demandas e motivações e valores culturais, como estudos, trabalhos, outros, num espaço-tempo para encorajar o indivíduo.

v.O encadeamento das estratégias como função do padrão das competências: a abordagem baseada em estratégias coloca-se a ênfase em padrões e na dinâmica de comportamento das competências individuais. O padrão é definido pela função de modelagem dinâmica $\Omega$ e sua inter-relação com as características comportamentais dos indivíduos e da relação de dependência das competências individuais $(\mathrm{CI})$ em relação às competências desejadas $(\mathrm{CD})$, isto é $f(\mathrm{CI} / \mathrm{CD})$, da seguinte forma:

$$
\mathbf{P}(\mathbf{E})=\mathbf{\Omega}\{\mathrm{CI}, f(\mathrm{CI} / \mathrm{CD})\}
$$

vi.O Padrão da Rede como função do encadeamento das estratégias: a abordagem baseada em rede coloca ênfase em padrões e na dinâmica das estratégias na formação das competências individuais. O padrão é definido pela função de modelagem dinâmica $\Omega$ e sua inter-relação com as características das estratégias e da relação de dependência das competências individuais (CI) em relação às competências desejadas $(\mathrm{CD})$, isto é $f(\mathrm{CI} / \mathrm{CD})$, da seguinte forma:

$$
\mathbf{P}(\mathbf{R})=\mathbf{\Omega}\{\mathrm{E}, f(\mathrm{CI} / \mathrm{CD})\}
$$

vii.Características da aprendizagem dos indivíduos em rede (ambiente) no espaço-tempo (A): Para agregar as características da aprendizagem no espaço-tempo e representar a rede, cria-se o 
termo Estado sendo definido como o conjunto de condições do ambiente (rede) em que estão situados os indivíduos e suas características, em determinados momentos. Tais estados variam desde o início até a finalização (Estado 1, Estado 2,..., Estado $N$, Estado $N+1$ ) do programa ou módulo de EAD. Para um indivíduo I, iniciando um módulo ou programa qualquer (Estado 1) com aprendizagem 1, em direção à aprendizagem 2 (Estado 2) qualquer, existirá um Período de Tempo PT em que começa e termina o programa, um Tempo T, um Modo M, Tipos de Atividades Pedagógicas TA, na rede $\mathbf{R}$, no qual tem-se o acréscimo da competência $\mathbf{C}$, que motiva o indivíduo.

viii.Características da formação de competências dos indivíduos no espaço-tempo: Para formar (agregar) as competências no espaço-tempo cria-se o termo Estado sendo definido como o conjunto de condições do ambiente (rede) em que estão situados os indivíduos e suas características, em determinados momentos. Tais estados variam desde o ingresso ao programa ou módulo de EAD até a sua finalização (Estado 1, Estado 2,..., Estado $N$, Estado $N+1$ ). Para um indivíduo I, iniciando um módulo ou programa qualquer (Estado 1) com competência 1, em direção à competência 2 (Estado 2) qualquer, existirá um Período de Tempo PT em que começa e termina o programa, um Tempo T, um Modo M, Tipos de Atividades Pedagógicas TA, na rede R, no qual tem -se o acréscimo da competência $\mathbf{C}$, que motiva o indivíduo.

ix.Execução das atividades no espaço-tempo (E): Para uma dada motivação de cada indivíduo tem-se a passagem de vários estados (Estado 1, ..., Estado $N$ ) ao longo do tempo, até a formação da (s) competência (s). Em cada estado o indivíduo seleciona um conjunto de atividades a ser desenvolvido, bem como o tempo necessário para executar tais atividades programadas. A estrutura individual (técnica e humana), como acesso a computadores, à internet, o ritmo de aprendizagem, as experiências, as oportunidades e restrições do local (espaço que o indivíduo se encontra) são alguns fatores que determinam a viabilidade das estratégias e conseqüentemente, o desempenho e a dinâmica da rede (do sistema).

x.Medidas do nível de dependência dos indivíduos em relação ao sistema: A medida da relação de dependência dos indivíduos (DI) em relação ao sistema (DS), $\boldsymbol{f}$ (DI/DS) estará definida, entre outras, pelas características do sistema de EAD (Rede).

xi.As características dos FCS e seus componentes influenciam diretamente as decisões de planejamento de capacitação a distância (em redes de conhecimentos). A inter-relação dos fatores altera as decisões que afetam o desempenho do sistema EAD.

xii.Competências individuais: $\mathrm{Na}$ abordagem baseada em redes de conhecimento (EAD), as competências individuais $(\boldsymbol{C I})$ são identificadas e analisadas a partir dos fatores críticos de sucesso $(\boldsymbol{W})$. A partir deste fundamento, representam-se os graus de avaliação de competência real (GACR) e desejado $(\boldsymbol{G A C D})$ dos indivíduos, "ex-ante" e "ex-post" (GACR) ao programa de capacitação. As competências individuais são dimensões que dinamizam a seleção de estratégias, conforme o grau 
de intensidade e, por isso, devem ser consideradas como elemento estratégico em planejamento de estratégias na rede de conhecimentos (EAD).

xiii.As estratégias como função das competências: Como um problema de hierarquização, as estratégias (E) são definidas a partir da discrepância resultante do grau de avaliação de competências (GAC), "ex-ante" e "ex-post" ao programa de capacitação (curso), em que as entradas são os elementos estratégicos e a saída é o grau de classificação do desempenho das estratégias ao término do programa de capacitação. Há uma inter-conexão entre as estratégias e podem ser definidas pela relação de dependência das competências individuais (CI) real e as competências desejadas (CD). Se as competências individuais e competências desejadas são definidas em função dos fatores críticos de sucesso, assim expressas:

$$
\begin{aligned}
& \text { CI é } f\left(W_{n}\right) \\
& C D \text { é } f\left(W_{n}\right)
\end{aligned}
$$

E se a relação entre as competências individuais e desejadas resulta o grau de avaliação de competências, expressa por:

$$
(\mathrm{CI} / \mathrm{CD})=\mathbf{G A C}
$$

Então, tem-se que:

\section{$\operatorname{GAC}(C I / C D)$ é $f\left(W_{n}\right)$}

vi. Comportamento dinâmico: A modelagem do comportamento dinâmico da rede de conhecimento (Seufert; Seufert, 1999; Seufert; Back; Häusler, 2001; Reisman; Dear; Edge, 2001; Castells, 1999; Castells, 2002) $=\mathbf{\Omega}$ \{Indivíduos (I) (Lito; Formiga, 2008; Moore; Kearsley, 2007) e das interações entre as dimensões qualitativas no espaço-tempo, será representada através de uma função de modelagem dinâmica $\mathbf{\Omega}$, que possibilitará expressar de forma realista as inter-relações dinâmicas observadas nas decisões individuais que afetam o sistema de EAD. Para isso, estabelecem-se o Indivíduo (I) os Fatores Críticos de Sucesso (W) (Rockart, 1979; Kahaner, 1996; Volery; Lord, 2008; Romiszowski, 2003) as Competências (C) (Mâsh, 2005; Parry, 1988; Parry, 1996; Cooper, 2000; Gramigna, 2002) e Estratégias (E) (MINTZBERG et. al., 2006; THOMPSON Jr.; STRICKLAND, 1996; THOMPSON Jr.; STRICKLAND, 2000). Assim, o comportamento dinâmico da rede de conhecimentos (EAD) $\boldsymbol{\Omega}$ da modelagem seria definido pelos seguintes elementos:

$\mathbf{R}=\mathbf{\Omega}\{$ Indivíduos $(\mathbf{I})$ Fatores Críticos de Sucesso $(\mathbf{W})$ as Competências $(\mathbf{C})$ Estratégias $(\mathbf{E})\}$

\section{Restrições da Modelagem}

Recursividade: as condições do Estado precedente "Estado (N)" influem no Estado seguinte "Estado $(\mathrm{N}+1)$ "; e 
Linearidade: as condições do Estado seguinte "Estado $(\mathrm{N}+1)$ " não são influenciadas pelo estado precedente "Estado (N)".

Simultaneidade na formação das competências: a formação das competências não segue um padrão excludente, isto é, a formação dos conhecimentos, habilidades e atitudes (competências) pode acontecer ao mesmo tempo.

Continuidade Temporal: representa o limite de tempo "ex-ante" e "ex-post" ao programa ou módulo de EAD na formação de competências individuais.

\subsection{Formulando a arquitetura das estratégias na rede de conhecimentos do modelo}

A função de modelagem dinâmica que permite representar a rede de conhecimentos é $\boldsymbol{\Omega}$, estabelecendo a relação entre os diferentes elementos que condicionam a rede, através da seguinte relação: $\mathbf{R}=\mathbf{\Omega}\{$ Fatores Críticos de $\operatorname{Sucesso}(\mathbf{W})$ as Competências $(\mathbf{C})$ Estratégias $(\mathbf{E})$ \}. A rede de conhecimentos como função das dimensões (fatores críticos de sucesso, competências e estratégias) é definida pela função de modelagem dinâmica $\boldsymbol{\Omega}$ e sua inter-relação com as características dos FCS do curso/indivíduo, e a relação de dependência das competências individuais em relação às competências desejadas, isto é $\boldsymbol{f}(\mathbf{C I} / \mathbf{C D})$, e das competências individuais em relação às estratégias $\boldsymbol{f}(\mathbf{C I} / \mathbf{E})$, da forma seguinte:

Seja a função da modelagem dinâmica representada pela seguinte relação:

$$
\left.\mathbf{E}_{\mathbf{n}}=\left\{(\mathrm{CI} / \mathrm{CD}), \boldsymbol{f} \mathbf{W}_{\mathbf{n}}\right)\right\}
$$

Considerando que: $\mathbf{C I}$ por $\mathbf{C}=$ conhecimento, $\mathbf{H}=$ habilidade, e $\mathbf{A}=$ Atitude, tem-se: $\mathbf{C I}=\mathbf{C H A}$

$$
\text { Se, } \mathbf{R}=\Omega f\left(\mathbf{E}_{\mathbf{n}}\right),
$$

Então, tem-se a partir desta formulação e dos objetivos propostos na presente tese, o modelo que reproduzirá a dinâmica das estratégias na rede de conhecimentos estará expresso por:

$$
\dot{R}=\Omega f\left\{\left(\left(\mathrm{CHA}_{\mathrm{I}} / \mathrm{CHA}_{\mathrm{D}}\right), \boldsymbol{f}\left(\mathrm{W}_{\mathrm{n}}\right)\right)\right\}
$$

E se a variação no grau de avaliação das competências (AGAC) é resultado da relação entre as competências individuais pelas competências desejadas $(\mathbf{C H A} / \mathbf{C H A})$, então:

$$
\dot{R}=\Omega f\left\{\left((\Delta \mathrm{GAC}), f\left(\mathrm{~W}_{\mathbf{n}}\right)\right)\right\}
$$

Onde Ŕ estará representado pela dinâmica das estratégias na rede de conhecimentos. E a medida da relação de dependência das competências $\mathbf{C H A}$ em relação as estratégias $\boldsymbol{f}\left(\mathbf{E}_{\mathbf{n}} / \mathbf{C H A}\right)$ estará definida, entre outras, pelas características do sistema de EAD.

Admitindo ainda que a relação funcional entre as variáveis seja linear. E que a variável 
dependente relaciona-se linearmente com as variáveis explicativas, agregam-se os seguintes parâmetros $\beta_{1,} \beta_{2} \mathrm{e} \beta_{3}$ à equação 1.5:

$$
\dot{R}=\mathbf{B}_{1+} \Omega f\left\{\left(\left(\boldsymbol{\beta}_{2} \Delta G A C\right), f\left(\beta_{3} W_{n}\right)\right)\right\}
$$

Em que: $\beta_{1} \beta_{2}$ e $\beta_{3}$ são os parâmetros do modelo (estatística da amostra). Em que, $\beta_{1}$ é o intercepto e $\beta_{2}$ e $\beta_{3}$ são coeficientes de inclinação. São chamados de coeficientes de regressão linear. A precisão dos estimadores lineares é elaborada pelo método MQO (Mínimos Quadrados Ordinários).

Considerando que as relações entre as variáveis são inexatas, agrega-se ao modelo a variável u (variável aleatória estocástica) expressa da seguinte forma (1.6):

$$
\dot{R}=\beta_{1+} \Omega f\left\{\left(\left(\beta_{2} \Delta G A C\right), f\left(\beta_{3} W_{n}\right)\right)+u_{i}\right\}
$$

Substituindo GAC por $\mathrm{X}_{1}$, e Wn por $\mathrm{X}_{2}$ para fins de ajuste de terminologia do modelo, temse (1.7):

$$
\dot{R}=\beta_{1+} \Omega f\left\{\left(\left(\beta_{2} \Delta X_{1}\right), f\left(\beta_{3} X_{2}\right)\right)+u_{i}\right\}
$$

Em que u é a soma de todas as variáveis que afetam o modelo, mas que não são consideradas explicitamente. O termo de perturbação u é um substituto de todas as variáveis explicativas $X$ omitidas do modelo, mas que coletivamente afetam $y$. O grau de ajuste global do modelo foi medido pelo coeficiente de determinação, $r^{2}$. Foi utilizado ainda o teste " $F$ " verificar a estabilidade estrutural do modelo. Este teste permite ainda decidir pela adição ou não de outras variáveis ao modelo, o que possibilita um incremento ao modelo. De posse da elaboração da modelagem, o passo seguinte é verificar a modelagem. Isto foi possível por meio de um conjunto de métodos integrados entre si.

\section{Método para verificação da modelagem}

Para demonstrar a factibilidade do modelo foi realizada uma aplicação em um curso de EAD aplicado em projetos de parcerias público-privadas (PPPs/Concessões de rodovias no Brasil), por meio de um MBA, num universo de cinqüenta alunos. $\mathrm{O}$ universo de pesquisa foi constituído por especialistas, selecionados por critério técnico-científico, com conhecimento sobre o objeto de estudo: (i) especialistas em elaboração e implementação de projetos de PPPs/concessões de rodovias no Brasil; (ii) especialistas em gestão de recursos humanos; (iii) especialistas em educação e EAD; (iv) especialistas em psicologia organizacional e gestão de pessoas; e por fim (v) especialistas em modelagem. A seguir detalham-se as fases e etapas.

Fase 1: Tomada de Decisão e Solução de Problemas: Como fase preparatória deste modelo de referência, a estruturação do problema de pesquisa foi elaborada á luz da Metodologia 
dos Sistemas Flexíveis - "Soft Systems Methodology (SSM)". A técnica "Brainstorming" e preferência declarada serão utilizadas como apoio na coleta dos dados.

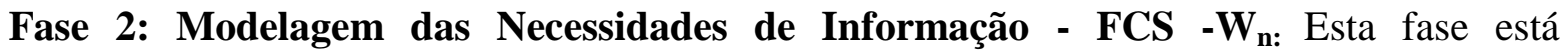
subdividida em: modelagem dos FCS e modelagem das áreas de informação.

Etapa 1: Modelagem dos FCS: A identificação dos FCS será inicialmente a partir de uma satisfatória revisão da literatura especializada e combinada com diversos métodos (LEIDECKER e BRUNO, 1984; ROCKART, 1979): (i) análise ambiental; (ii) análise estrutural da indústria; (iii) consulta a especialistas (negócio); e (iv) fatores temporais / intuitivos. A intervenção de especialistas é determinante no julgamento dos FCS. Uma vez identificados os FCS, o passo seguinte é agrupá-los para sua melhor compreensão, utilizando a técnica de "cluster", atendendo ao princípio da arborescência, que permite o desdobramento dos FCS em diferentes processos ou áreas envolvidas, mas observando-se sempre as relações de pertinência. Logo após a organização dos grupos dos FCS, à luz de cada "cluster" (elementos e subelementos), o passo seguinte é aplicar o método de escalagem psicométrica LJC de Thurstone (1927) para avaliar os FCS agrupados, ou seja, priorizar os "clusters", escalonando-os. Os resultados evidenciam a seguinte classificação: $\left(1^{\circ}\right)$ Político/Jurídico; $\left(2^{\circ}\right)$ Técnico; $\left(3^{\circ}\right)$ Econômico e Financeiro e $\left(4^{\circ}\right)$ Mercadológico.

Etapa 2: Modelagem das Áreas de Informação - AIs: Uma vez selecionados os FCSs, inicia-se a definição das Áreas de Informação (AIs) em função da respectiva afinidade com os diferentes componentes dos FCS. Por AI entende-se o local que recebe informações críticas para a construção e gerência dos projetos (aplicação - objeto de estudo). A confirmação das AI deve ser por meio de entrevistas / consultas aos especialistas. Para avaliar as AIs será utilizado o método LJC de Thurstone (1927). Os resultados produzidos são os seguintes: (1ª) Política; (2a) Econômica e Financeira; $\left(3^{\mathrm{a}}\right)$ Técnica; e (4 $\left.4^{\mathrm{a}}\right)$ Mercadológica.

Etapa 3: Desempenho das AIs em Relação aos FCS: Com a determinação das AIs é possível identificar sobre qual delas é necessário enfatizar a coleta de informação. Esse procedimento pode ser desenvolvido com o apoio dos métodos multicriteriais: "Compromise Programming", "Promethee II" e "Electre III". Os resultados apresentam a seguinte classificação de desempenho das AIs: (1 $\left.1^{\mathrm{a}}\right)$ Política; (2a) Mercadológica; $\left(2^{\mathrm{a}}\right)$ Técnica; e $\left(3^{\mathrm{a}}\right)$ EconômicoFinanceira.

Fase 3: Modelagem das Competências - CI é $\boldsymbol{f}\left(\mathbf{W}_{\mathbf{n}}\right)$ : Reunindo as dimensões propostas na construção de um modelo de avaliação de competências, aqui denominadas (DURAND, 1998 e 1999): conhecimentos, habilidades e atitudes, estruturadas em três etapas a saber: Etapa 1: definição do conceito; Etapa 2: identificação e captura; e Etapa 3: avaliação. As três dimensões serão identificadas a partir da literatura consultada e confirmadas junto a especialistas. Passa-se a sistematizar a primeira delas. 


\section{Conhecimento}

Etapa 1: Definição do Conceito de Conhecimento (NONAKA, 1991; NONAKA; TAKEUCHI, 1997; PROBST; STEFFEN; ROMHARDT, 2002; LAHAIE, 2007; SEUFERT, 1999): Passa-se a sintetizar os principais conceitos e elementos extraídos para os fins que ensejam este trabalho. Procede-se à seleção de fontes segundo sua relevância. A definição que permeia esta aplicação segue a proposta de Moresi (2001): dados (processamento) informação (elaboração) conhecimento (síntese) inteligência, respectivamente. Dado - conjunto discreto e objetivo de fatos sobre um determinado evento ou objetos. É portando, a parcela quantificável e objetiva do estoque de informação e conhecimento de uma empresa, e está armazenado em bancos de dados ou documentos da empresa. Informação: mensagem contendo um emissor e um receptor e cujo significado envolve uma nova interpretação de algo, baseado em um conjunto de dados. Conhecimento: é uma mistura fluida de experiências, valores, teorias, informação de contexto e intuição, formando um "framework" (um painel) na mente de uma pessoa que a habilita a interpretar, avaliar e tomar decisões acerca de casos, experiências e/ou informações. $\mathrm{O}$ termo conhecimento é definido, portanto, como algo que não pode ser totalmente estruturado (nãopapável), impossível de ser totalmente capturado e ter sua lógica dissecada (desestruturada), e que, por tudo isso, está presente somente dentro das pessoas. Mas ainda, o conhecimento só se manifesta quando é utilizado. Stair e Reynolds (2002) ressaltam que o "conhecimento representa a percepção e a compreensão de um conjunto de informações e de como estas informações podem ser úteis para uma tarefa específica". "O conhecimento pode ser dito como sendo aquilo que cada indivíduo constrói como produto do processamento, da inter-relação entre interpretar e compreender a informação [...]" (LITO; FORMIGA, 2008). Deste conjunto, origina-se uma característica importante desta definição de conhecimento: sua orientação para ação. O conhecimento só se materializa quando empregado e, quanto maior o conhecimento de uma pessoa, mais rica e frutífera será sua apreciação e análise dos dados e informações disponíveis. Conseqüentemente, maior a qualidade das decisões tomadas durante sua rotina diária nas empresas (DAVENPORT; PRUSAK, 1998).

Conhecimento segue ainda a lógica de Davenport e Prusak (1998), é a informação mais valiosa porque precisamente alguém deu a ela um contexto, um significado, uma interpretação, alguém refletiu sobre o conhecimento, acrescentou a ele sua própria sabedoria, considerou suas implicações mais amplas. Davenport (2001), Moresi (2001); Bukowitz e Williams (2002); Probst et al. (2002) salientam que conhecimento é a informação elaborada, refinada, avaliada sobre a sua confiabilidade, sua relevância e sua importância. E é por meio da síntese da informação, que há a conversão da informação em conhecimento. Após esta síntese, reúne-se a informação em blocos de tal forma que posteriormente possam ser utilizados por especialistas que filtram-na e padronizam-na 
para aplicá-la a uma situação específica. Uma vez exposta essa corrente de elementos definidores de "Conhecimento", adotam-se as "Informações de Contexto - (IC)" e as "Bases Teóricas e conceitos - (BTC)" como definição de conhecimento na presente aplicação.

Por informações de contexto entendem-se as informações analisadas e avaliadas a partir das áreas de informação levantadas na Fase 2, onde tais informações foram identificadas e capturadas (ambiente interno e externo, a partir da literatura especializada e por meio de entrevistas (formulário semi-estruturado) junto a especialistas, conforme a necessidade de alimentar o desenvolvimento das atividades e ações ali articuladas, para viabilizar projetos. Tais informações são elementares para a eficiência e sucesso de tais projetos. Por Bases Teóricas e Conceitos, entendem-se as habilidades conceituais. Por habilidades conceituais entendem-se as habilidades que envolvem a visão da organização ou da unidade organizacional como um todo, a facilidade em trabalhar com idéias e conceitos, teorias e abstrações. As habilidades conceituais estão relacionadas com o pensamento, o raciocínio, o diagnóstico das situações e a formulação de alternativas de solução dos problemas. Representam as capacidades cognitivas mais sofisticadas do gestor e que lhe permite planejar o futuro, interpretar a missão, desenvolver a visão e perceber oportunidades onde ninguém vê (CHIAVENATO, 1999). Na seqüência aborda-se a forma como esse conhecimento será identificado e capturado.

Etapa 2: Identificação e Captura do Conhecimento: A identificação do conhecimento é a primeira etapa do processo da Gestão do Conhecimento. São duas as frentes a serem analisadas: informações de contexto e bases teóricas e conceitos. As informações de contexto serão identificadas, capturadas e mapeadas ainda na feitura da Fase 1, por meio de entrevista e formulário semi-estruturado aplicado e confirmado junto aos especialistas com conhecimento sobre o objeto de estudo/aplicação, por áreas de informação (do objeto de estudo/aplicação). Sendo assim, uma vez identificadas e capturadas, serão nesta fase, elaboradas, analisadas e avaliadas para se tornarem compreensíveis aos tomadores de decisão (usuários da informação) na montagem e gestão dos projetos, objeto de aplicação, seguindo a analogia e hierarquia de dado, informação e conhecimento. Em seguida, essas informações serão revisadas e organizadas e validadas por especialistas envolvidos direta ou indiretamente com o objeto de aplicação (no caso, os projetos de PPPs). O procedimento para identificar as informações parte da determinação das teorias e conceitos relevantes que são necessários para viabilizar a consecução / operacionalização da montagem e gerência de tais projetos. Prossegue-se então rumo à captura deste conhecimento já identificado (Fase 2). “Após analisar e validar as informações, estas passarão ao estágio de conhecimento, ou seja, a informação compreendida. É por meio do conhecimento que aqueles que assessoram as decisões buscam uma compreensão mais efetiva da situação problema” (MORESI, 2001). E essas informações analisadas e avaliadas produzem o conhecimento, que é a informação elaborada, 
refinada, avaliada sobre a sua confiabilidade, sua relevância e sua importância. O conhecimento é obtido pela interpretação e integração de vários dados e informações para iniciar a construção de um quadro de situação (Moresi, 2001; Bukowitz e Williams, 2002; Probst et. al., 2002), e sugere os seguintes métodos como instrumentos de análises das informações: Análise SWOT, Sinergias, "Benchmarking”, Perfis Gerenciais, Monitoramento Tecnológico, Análise Morfológica, Análise Competitiva Dinâmica de D`Aveni, Cadeia de Valores de Porter, e Técnica de Cenários. Neste trabalho foi usada a Análise SWOT. A aquisição do conhecimento envolve a extração, interpretação e representação do conhecimento de um dado domínio e é considerado como sendo o estágio mais difícil e precário. O processo de captura representa a aquisição de conhecimentos e experiências necessárias para criar e manter as competências essenciais e áreas de conhecimento selecionadas e mapeadas. Capturar o conhecimento dos especialistas implica, segundo Buchanan (1999), em obter informação dos especialistas e/ou fontes de documentação, classificar essa informação de forma declarativa ou procedural, codificar essa informação num formato utilizado pelo sistema e validar a consistência do conhecimento codificado com o conhecimento existente no sistema. Assim sendo, o procedimento adotado é abordar a forma como será realizada a conversão da informação ao estágio de conhecimento, que é a informação a ser compreendida e útil na tomada de decisão em projetos. Num primeiro momento, coletam-se as informações. Em seguida estabelecem-se a combinação e a interiorização através do conhecimento, de explícito para explícito, pois as informações já estão mapeadas, formalizadas, para que ela seja melhor compreendida e sintetizada de forma a ser apresentada conforme todos tenham um entendimento mais fácil e rápido quando for possível (a informação deve ser útil na tomada de decisão. Para isso, deve ser compreendida). A simples atividade de comparar e contrastar informações é uma forma de análise. Eis alguns procedimentos para capturar o conhecimento: (Thiel, 2002): Entrevista, Mapeamento da Informação, Mapeamento do conhecimento e Conversação. Para converter a informação ao estágio de conhecimento (transformação), adota-se o seguinte procedimento: em primeiro lugar, (i) estabelece-se a comparação de como as informações relativas a uma determinada situação pode ser comparada a outras situações conhecidas; em segundo lugar, (ii) analisam-se e avaliam-se as implicações que as informações trazem para as tomadas de decisões; em terceiro lugar, (iii) estabelece-se a relação entre um novo conhecimento com o conhecimento acumulado; em quarto lugar, (iv) certifica-se o que os tomadores de decisão esperam da informação.

A conversão da informação em conhecimento conta com o apoio dos mapas de informação, elaborados na fase anterior por área, por meio de análise e avaliação da informação. É bom ressaltar que as informações consideradas são tanto as de origem externas como as internas. As informações de origens externas têm por finalidade principal detectar, com antecedência, oportunidades ao projeto em um futuro mais remoto (CÉLIS, 2000). As informações internas são importantes para 
estabelecer as estratégias, mas elas devem ser mais abrangentes do que a utilizada para a gestão operacional, pois além de permitir a avaliação do desempenho, ela tem a importante finalidade de identificar forças e fraquezas (CÉLIS, 2000).

Na sequência, abordam-se os procedimentos para a captura das bases teóricas e conceitos. Esse procedimento (I) inicia-se tomando por base as áreas de informação, uma a uma, em que serão então, identificados os conceitos e teorias que fundamentam o desempenho das ações (articulações) desenvolvidas nas referidas áreas de informação que permitem assegurar a viabilidade dos projetos. Ou seja, quais os conceitos e teorias são necessários conhecer para assegurar o desenvolvimento das atividades e ações para que os projetos sejam bem sucedidos, naquela área (identificada na Fase 2). Em seguida, (ii) prossegue-se então em analisar, por meio de pesquisas realizadas junto às instituições públicas e privadas (empresas, órgãos públicos, entre outros) sobre o mercado de profissionais demandados por essas instituições, suas competências, no caso conhecimentos, observando-se as exigências em áreas similares às contempladas neste trabalho (estudo comparado).

Do lado da oferta, busca-se pesquisar o nível de conhecimento demandado pelas empresas e outras organizações, nas referidas áreas, aliado a oferta no que tange à capacitação (forma, meios) dos profissionais (ou seja, que tipo de profissional está sendo demandado pelas instituições? Que tipo de profissional é ofertado para atender a essa demanda?).

Em seguida, agrupam-se os objetos de conhecimentos para sua melhor compreensão. Reagrupamento este, por "clusters", atendendo ao princípio da arborescência, que permite o desdobramento dos objetos de conhecimentos em diferentes processos ou áreas envolvidas, mas observando-se sempre as relações de pertinência, e complementados pelos métodos do Pareamento ou "cluster", com o propósito de reunir os dados amostrais em grupos (objetos de conhecimentos), classificando-os de tal forma que exista homogeneidade dentro do grupo e heterogeneidade entre os grupos (CRUZ; REGAZZI, 1994). Os resultados são apresentados à luz dos mapas mentais, com objetivo de capturar as visões dos especialistas e evidenciar a consistência na construção das idéias dos decisores na montagem e gestão de projetos de PPPs. Referencia-se a seguir uma análise comparada das Bases Teóricas e Conceitos e Informações de Contexto, um panorama geral. Os resultados das "informações de contexto" (IC) e "bases teóricas e conceitos" (BTC) são apresentados numa escala de -6 a 6: Gestão Governamental Políticas Públicas (GGPP), Econômica e Financeira (EF), Técnica (T), Mercadológica / Negócios (MN). Ao comparar as "IC" e "BTC", a categoria Econômica e Financeira e a Gestão Governamental Políticas Públicas são as categorias mais importantes. 
Figura 1: Variação da dispersão das preferências dos decisores - "Bases Teóricas e Conceitos" e "Informações de Contexto"

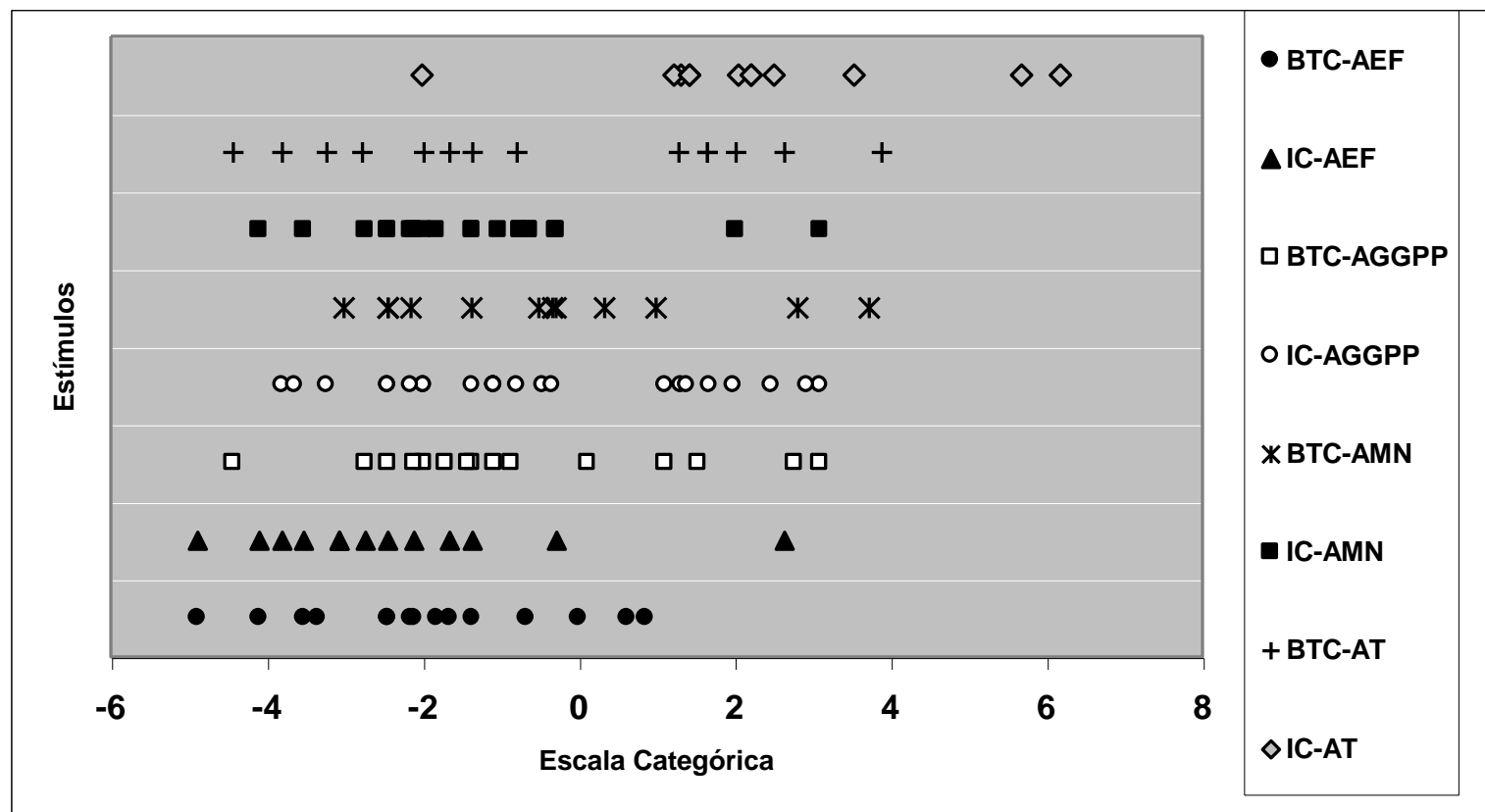

A amostra foi sistemática e não-probabilística, extraída a partir da literatura e confirmada junto a especialistas com conhecimento no objeto de estudo pesquisado, pessoas envolvidas com o objeto aplicação do estudo. $\mathrm{O}$ instrumento de coleta dos dados é um formulário, previamente testado, aplicado aos especialistas. Utilizam-se como instrumentos de apoio para avaliação dos objetos de conhecimentos (escalagem ou classificação ou priorização), os métodos dos (i) Julgamentos Categóricos de Thurstone (1927) (Souza, 1988) e as (ii) Redes Neurais Artificiais (RNA) VON ALTROCK, 1997; HAYKIN, 1999).

Figura 2: Avaliação dos Objetos de Conhecimentos - LJC e RNA

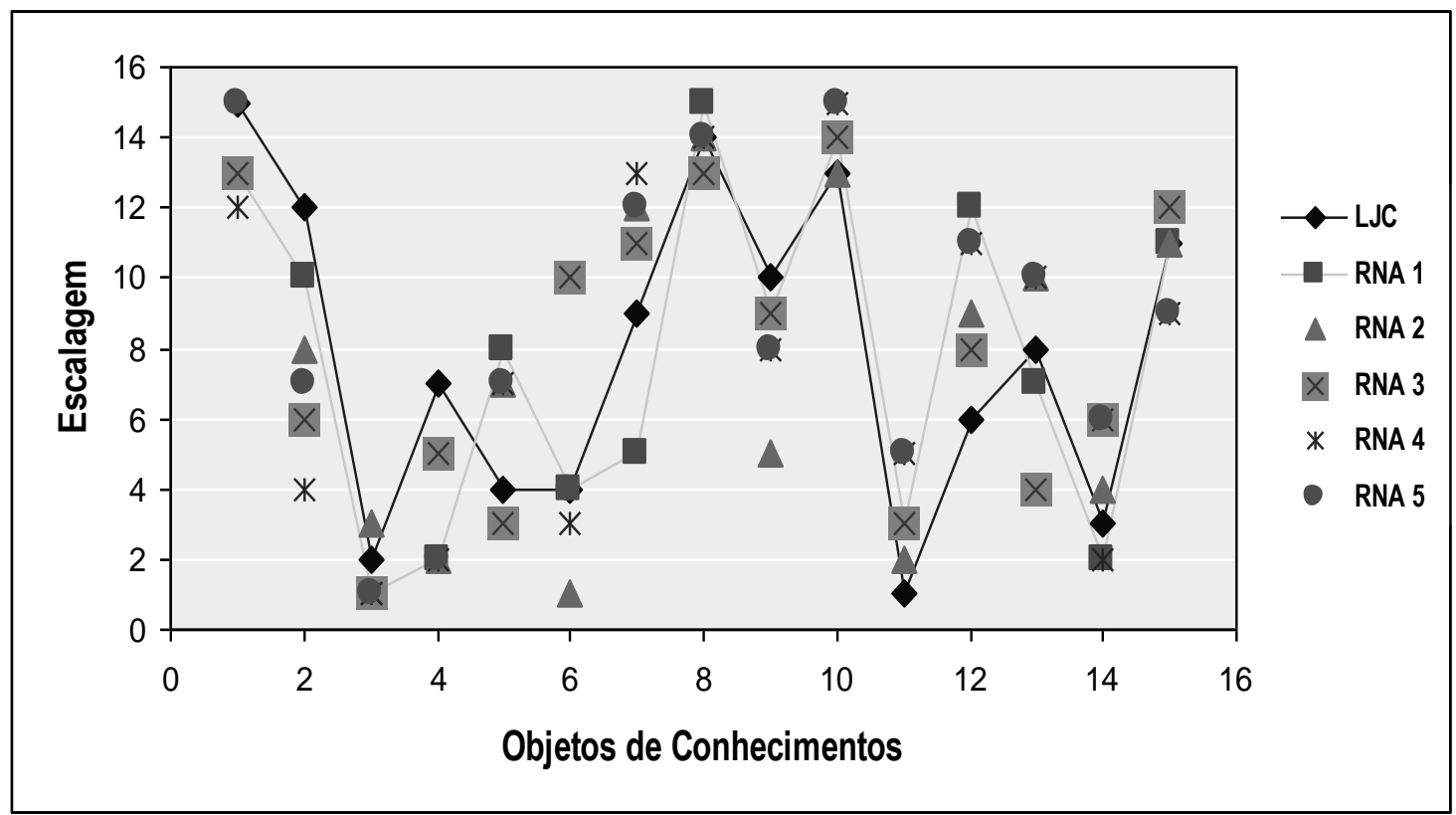

\section{Habilidades}


A dimensão que orienta o conceito de habilidades neste artigo é o de saber-fazer, como uma dimensão da competência. Os dados serão extraídos à luz da literatura e submetidos ao julgamento de especialistas para confirmação dos resultados. O instrumento de coleta dos dados é um formulário, previamente testado, aplicado aos especialistas (juízes). As habilidades (Chiavenato, 1999; Spencer e Spencer, 1993) serão organizadas utilizando-se o princípio da arborescência e análise de "cluster". A variável explicativa (habilidades) será medida por uma escala de itens pelo "método de Thurstone", LJC. Os resultados estão evidenciados na Figura 3.

Figura 3: Intensidade na preferência dos especialistas em relação às habilidades

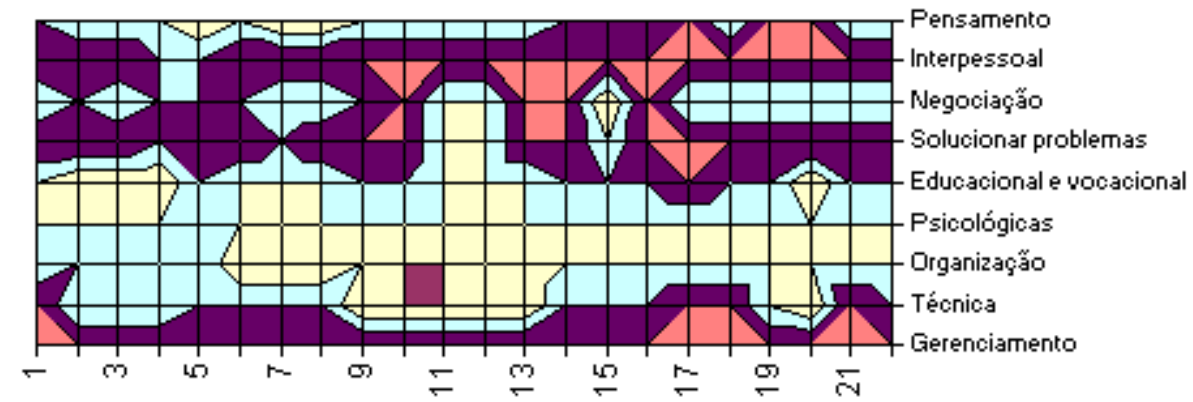

Atitudes: A partir da seleção e decantação da literatura são filtrados os seguintes elementos constituintes dos conceitos de atitudes: "afeição e sentimento" (THURSTONE, 1927). São as predisposições aprendidas a responder sobre um objeto ou a uma classe de objetos de forma consistentemente favorável ou desfavorável. Será selecionado o "método de Thurstone" ou dos "intervalos equi-aparenciais" para avaliação das atitudes. A amostra será sistemática e probabilística, extraída à luz da literatura e confirmada junto a especialistas com conhecimento no objeto de estudo pesquisado, pessoas envolvidas com a gestão de recursos humanos e psicólogos, entre outros. Os resultados são ilustrados na Figura 3. 
Figura 4: Intensidade na preferência dos atores em relação às atitudes

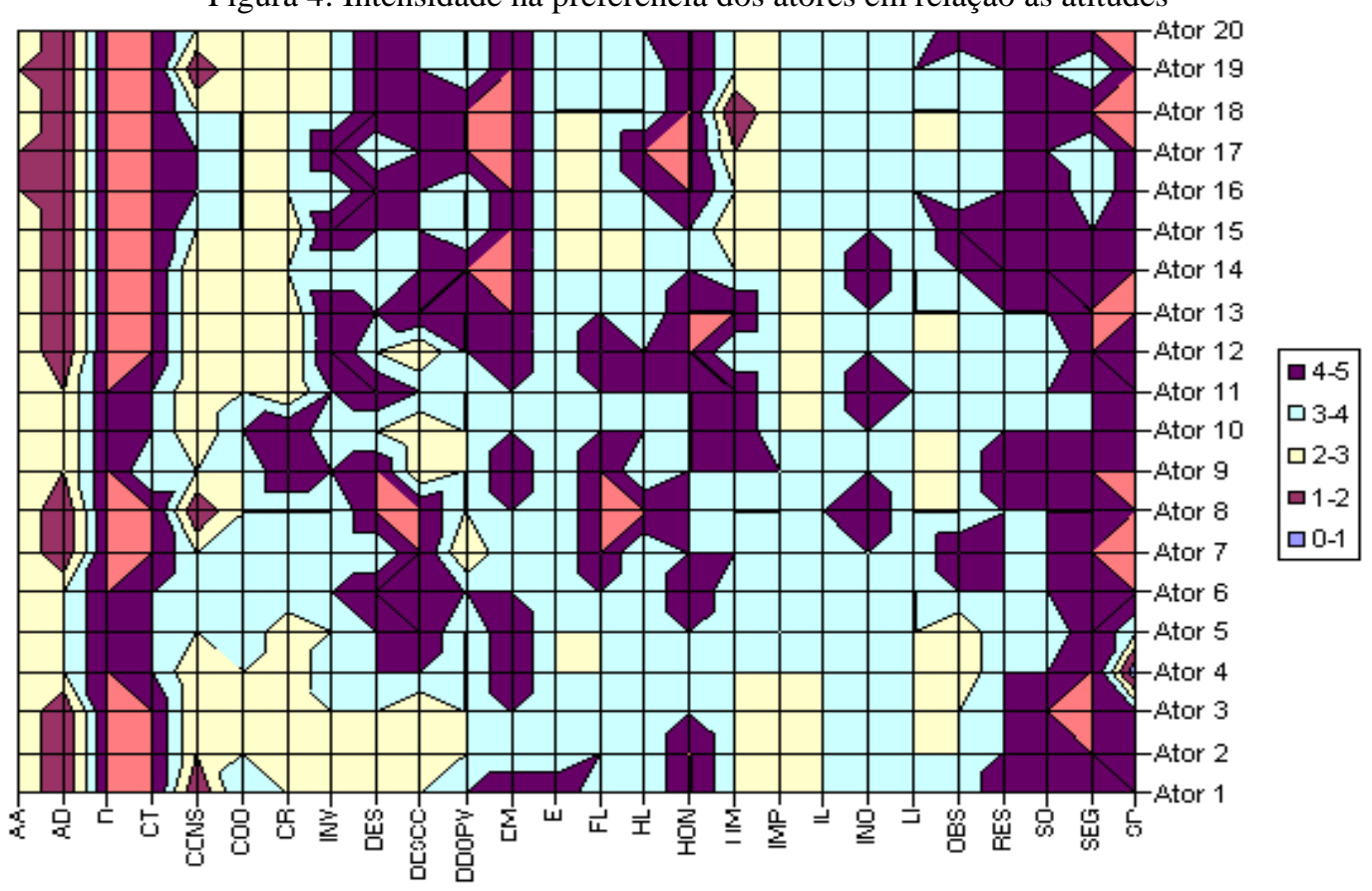

$\mathrm{Na}$ perspectiva dos pressupostos de um projeto de PPPs, as atitudes predominantes, priorizadas por importância, são: (CT) comprometer-se-cumpridor de tarefas; (DE)desafiarempreender; (DDOPV) determinado-dinâmico-ousado-proativoversátil; (EM) entusiasta-motivado; (E) ético; (FL) flexível; (HL) holístico-visão sistêmica; (HON) honesto-íntegro; (HM) humilde; (IM) imparcial; (IL) impor limites; (INO) inovar; ® responsável; (SO) saber ouvir; (S) seguro; e (SP) superar problemas-fracassos.

Fase 4: Determinação do Grau de Avaliação de Competências - $\mathbf{R}=\beta_{1+\Omega} f\{(($ $\left.\left.\left.\beta_{2} \mathrm{GAC}_{1}\right), f\left(\beta_{3} \mathrm{~W}_{2}\right)\right)+\mathrm{u}_{\mathrm{i}}\right\}$

Os resultados gerados nesta fase definem o padrão das estratégias da modelagem presente na rede de conhecimentos (EAD), a qual será elaborada na fase seguinte. A modelagem das estratégias resulta da variação entre os graus de competências (Desejado - D e Real - R) elaborados ainda nesta fase, em duas etapas: (i) determinação do GACD - Grau de avaliação de competência desejada para o desempenho das atividades e ações contempladas pelas AIs. 2) determinação do GACR - Grau de avaliação de competências reais. As competências reais são aquelas competências que o indivíduo possui no momento que antecede à participação no programa de EAD.

Etapa 1: Determinação do GACD: Para a obtenção do GACD será aplicada a tecnologia "neurofuzzy", que se apresenta como um instrumento viável para a modelagem, e está estruturado seguindo a analogia do modelo de Cury desenvolvido em 1999, com arquitetura hierárquica, que congrega os graus de avaliação atribuídos por especialistas (estimativas, "ex-ante”), numa interação de todos os dados em blocos de inferência que utiliza bases de regras "fuzzy" e expressões lingüísticas, que resulta em avaliação da competência, por meio de uma ponderação, que produz o 
grau de avaliação de competências (GAC) (CURY; VEIGA, 2004; CURY,1999).

Arquitetura da Rede Neurofuzzy: Em cada nó da rede, dois ou mais elementos são agregados num único elemento, dando origem a um novo nó, que por sua vez, também se agrega a outros nós, produzidos paralelamente, e dão origem a um novo nó. E assim por diante, até a obtenção do nó final. E a arquitetura da rede "neurofuzzy" (RNF) é definida pelas variáveis de entradas em sua primeira camada e sempre convergindo para seus nós de rede. Cada nó corresponde a uma base de regras "fuzzy", denominado de Bloco de Inferência (BI), no qual são computadas as variáveis lingüísticas, por agregação e composição, de modo a produzir um resultado inferido, também na forma de variável lingüística. Assim, nos BI da RNF definem-se as regras. Em síntese, as variáveis de entrada (VE) passam pelo processo de fuzificação e pelo bloco de inferência (BI), produzindo, em seguida, uma variável de saída (VS), denominada de variável intermediária (VI), caso não corresponda ao último BI da rede. Essa VI, por sua vez, junta-se com outra VI, formando um conjunto de novas VE, configurando, por conseguinte, uma seqüência a última camada da rede. Na última camada, também composta por VI, produz a variável de saída (VS) definitiva da RNF. Essa VS sofre, então, o processo de defuzificação para que o resultado final seja obtido: o GACD em análise. A seguir são descritos os procedimentos para determinação do GACR dos participantes de EAD "ex-ante". O valor do GACD numérico numa escala de 0 a 1 corresponde a 0,6428, resultante da média aritmética dos valores resultantes da defuzificação de cada um dos vinte juízes simulados. Este valor corresponde a um valor médio para o GACD.

Etapa 2: Determinação do GACR dos participantes - ex-ante: Reunindo as diversas dimensões que potencializam uma avaliação de competência, a seguir são apresentados os modelos aplicados neste artigo.

\section{Proposta de Tratamento}

Conhecimentos: Para conhecer o nível de conhecimentos dos participantes, serão aplicados testes/provas, com itens ou questões abertas. De posse dos resultados avaliados, procede-se um ajuste numa escala de 1 a 5, em que 1 representa o valor mínimo de importância ou de domínio no conhecimento e 5 representa o valor máximo.Em seguida calcula-se a média e o desvio-padrão de todos os participantes.

Habilidades: O levantamento das habilidades dos alunos será elaborado com base na listagem inicial das habilidades identificadas na fase anterior, e submetidas inicialmente nesta fase ao julgamento de juízes, usando a técnica Delphi. Para avaliar as habilidades dos estudantes os alunos são submetidos a uma escala do tipo "Likert", individualmente. Aplica-se o método LJC de Thurstone como instrumento confirmatório da escala "Likert". De posse dos resultados produzidos, ao conhecer o nível de habilidades de cada participantes investigado, na escala de 1 a 5, calcula-se a 
média e o desvio-padrão dos referidos grupos de habilidades dos participantes.

Atitudes: Utiliza-se a escala de "Likert", similar a apresentada no levantamento das habilidades. Será elaborado um questionário fechado com o objetivo de avaliar o grau de atitudes contempladas pelos alunos, em conformidade com as habilidades desejadas a serem aplicadas ao objeto de estudo da EAD (PPPs). Como instrumento confirmatório à escala de "Likert", utiliza-se o método de Thurstone LJC. Nesta perspectiva, os valores resultantes desta análise preliminar, média das dimensões, serão considerados ainda nesta etapa, variáveis de entradas para a modelagem "neurofuzzy", convergindo para o GACR. O resultado do GACR corresponde é 0,4246. A fase seguinte é definir a modelagem das estratégias de EAD à luz da variação entre os GACD e GACR, definidos "ex-ante" ao programa de EAD. A estratégias serão identificadas inicialmente pela literatura especializada e julgadas por especialistas. E logo após o encerramento do programa ou módulo (“ex-post”) serão comparados os GACD “ex-ante”, GACR “ex-ante”, e GACR “ex-post”, onde se serão verificadas se as competências desejadas foram ou não alcançadas. Detalha-se a seguir a modelagem das estratégias.

\section{Fase 5: Modelagem das Estratégias em Rede (EAD)}

$$
\dot{\mathrm{R}}=\Omega f\left\{\left((\Delta \mathrm{GAC}), f\left(\mathrm{~W}_{\mathrm{n}}\right)\right)\right\} \square \mathrm{R}=\beta_{1+} \Omega\left(\beta_{2} \mathrm{E}_{\mathrm{n}}\right)+\mathrm{u}_{\mathrm{i}}
$$

À luz dos resultados produzidos na fase anterior (fase 4) e com base na revisão da literatura, propõe-se uma modelagem para identificação das estratégias de capacitação a distância conforme as seguintes fases: (i) fase da análise e avaliação dos GACD e GACR, conforme a intensidade de suas variações individualmente. Fase (ii) Levantamento das Estratégias. A elaboração das estratégias está estruturada conforme o seguinte roteiro analítico: (i) fase da definição da missão e objetivo; (ii) fase da análise estrutural da indústria (EAD); (iii) fase da seleção dos elementos constituintes das estratégias; (iv) fase da definição das estratégias e critérios para uma estratégia eficaz; (v) fase do desenvolvimento das estratégias alimentadoras da rede de conhecimentos em PPPs; (vi) fase da emergência de ajustes de estratégias prioritárias. Detalham-se a seguir os resultados produzidos nessas fases.

Fase da definição da missão, tornar-se referência na formação de competências para PPPs, por meio da integração e interação das pessoas em rede de conhecimentos, viabilizados por tecnologias, mídias e outros sistemas.

Fase da análise estrutural da indústria (EAD), segundo as forças propostas por Porter. Aplicando a análise SWOT, tem-se: (i) Pontos fortes Internos Potenciais: (a) habilidades tecnológicas, de mídias e inovação; (b) gerência criativa em EAD; (c) produto fortemente diferenciado; (d) equipe forte de especialistas, sobretudo em conteúdo, poucos especialistas, mas de elevado potencial; (e) competência básica nas áreas chaves; (f) curriculum acreditado; (g) 
qualidade do corpo docente, especialistas; (h) instalações físicas, laboratórios, materiais instrucionais, outros. (ii) Pontos Fracos Internos e Potenciais: (a) Ausência de algumas competências chaves ; (b) pouca experiência da equipe em algumas áreas chaves; (c) investir mais fortemente em treinamento, sobretudo no gerenciamento de equipes, motivação, comunicação e liderança. (d) carência de treinamento; (d) poucos especialistas em conteúdo, o que pode ser um agravante, mais adiante; (e) custos; (f) acreditação; e outros. (iii) Oportunidades Externas Potenciais: (a) mercado potencial de investimentos em infra-estrutura financiado por PPPs, assim oportunidades de expansão nacional e global; (b) necessidade de capacitação de recursos humanos para as PPPs; (c) a EAD como um instrumento viabilizador de formação de competências para as PPPs, a todo momento e em qualquer lugar; (d) exigências no padrão de qualificação profissional no mercado de trabalho abre espaço para a EAD; (e) incremento na demanda; (f) reconhecimento; e por fim, (g) oportunidades de alianças estratégicas, especialização curricular; entre outros. (iv) Ameaças Externas Potenciais: (a) entradas de concorrentes no mercado nacional; (b) exigências legais provocando perturbações na política de EAD; (c) mudanças na política de investimentos, provocando viés em financiamentos viabilizados por PPPs, como a falta de incentivo governamental, buscando outra opção de financiamento; (d) novos entrantes no mercado; e (d) outros. A EAD tem experimentado desafios, uma agenda de estratégias é aqui apresentada, e sem dúvida, ao examinar as várias forças competitivas que pairam sobre o sistema de EAD foi determinante para algumas escolhas. A análise SWOT como instrumento de análise da situação atual do sistema de EAD permitiu traçar as seguintes diretrizes estratégicas: (i) recursos, capacidades existentes e limitações do sistema de EAD/PPPs; (ii) possibilidades de alianças e parcerias com colaboradores; (iii) adoção de um sistema de acreditação, como um indicador de qualidade do sistema; (iv) interação interpessoal, por meio de métodos e técnicas instrucionais e outros recursos tecnológicos com vistas a dotar alunos de educação de qualidade; (v) possibilidades de expansão do mercado global; e (vi) curriculum específico.

Fase da seleção dos elementos constituintes das estratégias, as escolas, as teorias, outros elementos de EAD, extraídos da literatura e confirmados junto aos especialistas. É elaborada uma seleção desses elementos combinados que vão contribuir na definição das estratégias. As estratégias de EAD a serem definidas mais adiante se orientam nas seguintes Escolas (citadas por Mintzberg et al., 2006): do Design e do Aprendizado, enfoque nas capacidades dinâmicas; do Planejamento, enfoque na análise de cenários; Cognitiva, enfoque no construcionismo, Ambiental, enfoque nas contingências; e da Configuração, enfoque no processo. E as principais teorias pedagógicas são: (i) teorias da independência e autonomia; (ii) teorias da industrialização do ensino; (iii) teorias da interação e comunicação. E se apóiam em três perspectivas de aprendizagem: (i) Associacionista; (ii) Cognitiva; e (iii) Situada. Essas referências conjugadas dão 
as diretrizes aos componentes estratégicos do sistema EAD. Eis alguns desses componentes (LITO; FORMIGA, 2008; MOORE; KEARSLEY, 2007): (i) Ambiente virtual; (ii) Tecnologias e Mídias; (iii) Conteúdo; (iv) Motivação e Interação; (v) Avaliação; (vi) Ensino; (vii) Aprendizagem, entre outros. A partir destes pressupostos são definidas na fase seguinte as estratégias de EAD.

Fase da definição das estratégias e critérios para uma estratégia eficaz. De posse dos resultados produzidos na fase anterior, foi possível identificar as seguintes estratégias: (i) estratégias de diferenciação: de imagem, de suporte, de qualidade, design; (ii) estratégias de personalização; (iii) estratégias de pacote; (iv) estratégias cognitivas; e (v) do Aprendizado. Neste espectro, definem-se como estratégias: (i) estratégias de diferenciação de imagem, de suporte, de qualidade, de design para: (a) ambiente virtual;(b) as tecnologias e mídias; (c) o conteúdo; (d) a motivação e interação; (e) avaliação; (f) ensino; (g) da aprendizagem; (ii) estratégias de pacotes, oferecer um conjunto de módulos encadeados e integrados para formar o pacote completo (Programa de EAD); (iii) estratégias cognitivas; (iv) estratégias de aprendizagem; e (v) estratégias de personalização.

Esta fase foi concebida à luz dos estilos de aprendizagem (EA) e das inteligências múltiplas (IM) predominantes nos participantes do programa ou módulo de EAD. Os EA são identificados utilizando o inventário de Felder e Salomon (1996), derivado do modelo desenvolvido por Felder e Silverman (1988). Os tipos de Inteligências Múltiplas foram extraídos a partir da proposta de GARDNER (1994). E para avaliar a eficácia das estratégias adotam-se os seguintes critérios (TILLES, 1963; CHRISTENSEN et al., 1978, citados por MINTZBERG et al., 2006): (a) clareza, (b) impacto motivacional, (c) consistência interna, (d) compatibilidade com o ambiente, (e) adequação à luz dos recursos, grau de risco, (f) combinação de valores pessoais com os principais números, (g) horizonte de tempo e funcionalidade. Outros critérios eficazes, segundo Mintzeberg et. al. (2006), guiam as ações: (i) objetivos claros, decisivos; (ii) manter a iniciativa; (iii) concentração; (iv) flexibilidade; (v) liderança coordenada e comprometida; (vii) surpresa; (viii) segurança.

O quadro de julgamento dos especialistas apresenta o desempenho das estratégias para assegurar as competências individuais e alcançar os objetivos pretendidos, GACD: (i) estratégias de aprendizagem; (ii) estratégias de diferenciação de qualidade e estratégias cognitivas; (iii) diferenciação de imagem; (iv) estratégias de personalização em massa; (v) estratégias de suporte; (vi) estratégias de diferenciação de design; (vii) estratégias de pacote, nesta ordem respectivamente. Ao analisar as lógicas internas dessas estratégias, os resultados produzidos mostram que as principais diferenciações de imagens referem-se ao ambiente virtual e avaliações. Na perspectiva da diferenciação de qualidade, as prioridades a serem atacadas são interação e motivação, conteúdo e aprendizagem. É fundamental ainda estabelecer esforços nas estratégias de suporte nos métodos e técnicas de interação e motivação, ensino e mídias e tecnologias. Ao analisar o design, requer 
potencializar o conteúdo e ambiente virtual. Ressalta-se ainda o relacionamento cooperativo e colaborativo, por meio das interações, no desenvolvimento do aprendizado e na formação das competências, resultante da inclusão e o senso de solidariedade das equipes, a facilidade de expressão e a síntese de vários pontos de vista, sem que um único aluno se destaque, são características importantes na construção social do conhecimento.

Um outro aspecto importante são as características da personalidade dos alunos de EAD, quando não são consideradas, pode resultar em disparidades na definição de estratégias. Os alunos mais independentes e autônomos, com menos influência do ambiente são mais preparados para a EAD. Conforme discussão anterior, os participantes deste programa de EAD são predominantemente ativo, global, verbal e seqüencial, contrapondo-se ao que Moore e Kearsley (2008) chamam de padrão identificação de alunos para a EAD, visual, cinestésico, introvertido, tátil e auditivo. Dado este descompasso, observa-se ainda a necessidade de levantar os tipos de inteligências predominantes dos alunos. E os resultados, já mostrados em seção anterior, são alunos com inteligências pessoais e lingüísticas predominantes. Esses resultados foram decisivos para as intervenções dos juízes ao julgarem as estratégias que mais se adéquam à realidade dos referidos perfis de alunos.

A imagem do conteúdo é fundamental para os alunos, observa-se que há uma probabilidade maior de desistências ao perceberem que o conteúdo é irrelevante ou de pequeno valor para suas carreiras ou interesses pessoais. A avaliação deve ser percebida pelos alunos como um instrumento necessário e motivador no processo de aprendizagem, o que requer traçar no planejamento um diagnóstico dos estilos e ritmos de aprendizagem dos alunos (avaliação diagnóstica) e definir as atividades que se ajustam a cada aluno.

Em quase todas as intervenções dos especialistas no processo de julgar as estratégias, a maioria deles foi enfática ao tratar as dimensões interações e motivações. Porém, todos foram unâmimes ao considerar o conjunto de estratégias igualmente importantes no processo de aprendizagem e sobretudo na formação das competências. Ainda é percebido que os alunos preferem o aprendizado tradicional em sala de aula, mesmo que o módulo tenha superado as expectativas do programa de EAD. As falhas existem, instrutores despreparados e inexperientes, falhas de equipamentos, e isto gera atitudes negativas em relação ao aprendizado a distância, mesmo que esses problemas também sejam presentes no ensino tradicional. $O$ desafio é desmistificar as atitudes negativas em relação a EAD, e neste espectro, as estratégias aqui propostas têm a pretensão de pelo menos servir de um roteiro nas políticas de planejamento em EAD.

O desenvolvimento das competências no campo das PPPs haverá de ser um esforço coletivo de todas as estratégias. Pois conclusões que hão de ser tiradas dos aspectos positivos e negativos do desenvolvimento das estratégias é oportunizar contribuições rumo à definição de políticas de 
planejamento cada vez mais inovadoras no campo da EAD. Os modelos de planejamento sempre foram impulsionados por ações decisivas já elaboradas; essa lógica haverá de ser mantida, só que abrindo cada vez mais espaços para os diversos estratos que se impõe como inovadores. Concretamente, o avanço na formação dos recursos humanos, a preparação das vastas camadas para se capacitarem tecnicamente, a democratização do ensino hão de ser diretrizes de uma nova política de planejamento em EAD, que compreenda que as necessidades coletivas são melhores atendidas de uma forma diversificada e inovadora. E neste espectro há de se resgatar a necessidade de um planejamento coletivo e integrado.

\section{Voltando ao Ofício da Modelagem}

A rede de conhecimentos é resultante da dinâmica das estratégias em $\mathrm{EAD}: \mathrm{R}=\Omega f\left(\mathrm{E}_{\mathrm{n}}\right)$, produzidas à luz da variação do GAC e dos FCS: $\mathrm{R}=\Omega f\left\{\left((\Delta \mathrm{GAC}), f\left(\mathrm{~W}_{\mathrm{n}}\right)\right)\right\}$. Considerando as características de dinamismo e flexibilidade do modelo, outras variáveis podem ser agregadas (ui). Sendo assim o modelo fica melhor especificado da seguinte forma: $\mathrm{R}=\beta_{1}+\Omega f\left\{\left(\left(\beta_{2} \mathrm{GAC}\right)\right.\right.$, $\left.\left.f\left(\beta_{3} \mathrm{~W}_{\mathrm{n}}\right)\right)+\mathrm{u}_{\mathrm{i}}\right\}$. A variável dependente $(\mathrm{E}=\mathrm{Y})$ é resultante da média ponderada das amostras das estratégias, e as variáveis independentes $(\mathrm{X} 1=\Delta \mathrm{GAC})$ e $(\mathrm{X} 2=\mathrm{FCS})$ são geradas a partir da média da variação dos GAC e da média dos FCS respectivamente. Esses valores foram então, submetidos a uma análise de regressão.

Figura 5: Reta de regressão da amostra baseados no dados dos FCS, $\triangle$ GAC e estratégias

\section{Plotagem de probabilidade normal}

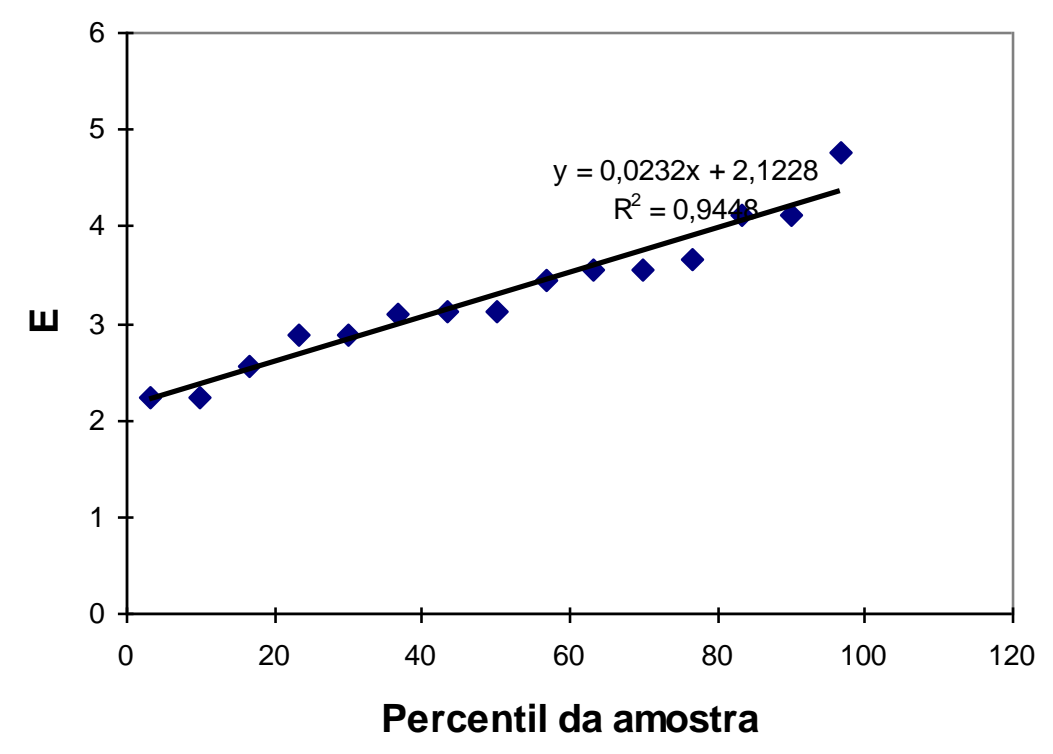

$\mathrm{O}$ valor de $\beta_{2}=0,0232$ mostra que quando $\mathrm{X}$ aumenta em $1 \%$, o aumento estimado das estratégias chega a 0,0232 . $O \beta_{1}=2,1228$ indica o nível médio de estratégias, por aluno, quando a 
variação no grau de avaliação de competências for praticamente nula. A estabilidade estrutural do modelo é verificada pelo teste "F", que é possível confirmar que o modelo é estatisticamente significativo, indicando que no conjunto, as variáveis explicativas têm forte influência estatística sobre a variável explicada. Já os resultados produzidos por $r^{2}$ referenciam que $94 \%$ da variação na média das estratégias em EAD é explicada pela variação no GAC e pelos FCS, e indica um ajustamento bastante satisfatório do modelo, ou seja, 94\% das variações nas médias das estratégias são explicadas pelas variáveis independentes. Se aumentar a média da variação do GAC e dos FCS, em 1\%, por aluno, a média das estratégias deve ser elevada em pelo menos 0,0232 por estratégia concebida. E se a variação no GAC fosse zero, e sem necessidade de alcançar qualquer FCS, mesmo assim, deveria contar com pelo menos 2,1228 de estratégias em EAD para manter pelo menos as competências individuais existentes. Espera-se que as competências dos participantes do programa de EAD sejam pelo menos mantidas.

\section{Palavras finais: lições aprendidas}

Encerra-se este documento sobre EAD no campo da Engenharia de Produção, evidentemente permanecem diversas questões a serem aprofundadas em outros estudos do gênero. Para estes novos estudos espera-se ter contribuído para discussão metodológica que ainda pode ser bastante explorada. Crê-se ainda na importância de se entender a EAD no sentido das necessidades da sociedade. Necessidades estas, criadas no seu devido contexto social, econômico e político.

É importante lembrar que a modalidade de EAD não é uma "panaceia" para resolver qualquer problema educacional. Contudo, acredita-se que, quando bem concebido, organizado e gerido, pode conduzir a resultados bastante positivos e com grande impacto, tanto em termos de expansão eqüitativa de acesso, como em termos de prestação dum serviço educativo de alta qualidade. Considerar a EAD como solução para carências educacionais e/ou rejeitá-la por qualidade insuficiente é colocar mal a questão, porque disfarça as questões mais importantes para a compreensão do fenômeno: seu caráter econômico, que determina muitas práticas, e suas características técnicas, que apontam para aquela "convergência de paradigmas", isto é, para a mediatização técnica dos processos educacionais.

Seja como for, as tentativas fracassadas de EAD cedem espaços para reforçar a importância de seu papel dando um salto para modelos mais inovadores e livres de riscos de errar. Não está substituindo um Poder de Polícia de controle das atividades e ações de alunos, e nem desprivilegiando o que já deu certo, mas fomentando o pragmatismo no implemento da EAD com responsabilidade. Aliás, o processo de formação de um modelo inovador de EAD inaugura uma nova forma de relacionamento aluno-professor: um relacionamento em que o aluno não se encontra mais capitaneado por quem ensina. 
Essa proposta visa, antes de tudo, que se iluminem questões ainda não exploradas neste objeto tão-complexo. Evidentemente, não pretende ser uma "camisa de força" metodológica, mas que venha prestar uma contribuição, mesmo que por caminhos mais livres. Além disso, esse suporte metodológico não tem a pretensão de ser completo, mas sim, de ser gerador de elementos do conhecimento que são estratégicos para o desenvolvimento de projetos de EAD. O que torna o espectro de decisão mais inteligente, disponibilizando elementos essenciais para a elaboração de projetos de EAD.

Por se tratar de uma temática tão relevante no contexto histórico atual de nosso País, recomenda-se que este estudo, dada a factibilidade demonstrada do método, seja continuado e atualizado de forma permanente e recorrente, permitindo o acompanhamento das mudanças ocorridas no contexto que se insere os projetos de EAD.

\section{Abstract}

This paper intends to contribute to the planning guidelines in the field of distance education (DE). Thus, it develops a multi-model reference proposal supported by the definition of a highly complex spectrum of strategies that considers a sequence of systematic procedures in the following phases: (i) Determining the information needs in two stages: (a) identification of the critical success factors (CSF), and (b) identification of the information areas; (ii) Determination of competences; (iii) Determination of the degree of competence evaluation; and (iv) Determination of strategies in knowledge networks. There is the application to a case study of the road concessions in Brazil, within the perspective of public-private partnerships (PPPs). The research was achieved through the intervention of specialists and a small group of students from a DE program (MBA) applied to the PPPs. Several support instruments were used in the modeling elaboration in order to reduce subjectivity in the results: psychometric scales - Thurstone's Law of Comparative Judgment (LCJ), multi-criteria Compromise Programming, Electre III, and Promethee II; Multivariate Analysis; Krigage, Artificial Neural Networking (ANN); Neuro-fuzzy networks. The results produced are satisfactory, validating the proposed procedure for DE.

Key-words: Distance education. Planning. Multi-model reference. Public-private partnerships (PPPs).

\section{Referências}

ABELES, T.P. (2005). Institutional change in the academy. On the Horizon, Vol. 13 No. 2. 2005.

\section{cross ${ }^{\text {ref }}$}

ALLAMA IQBAL OPEN UNIVERSITY. Disponível em: 〈httplwww.aiou.edu.pk>. Acesso em: 14 abr. 2008.

ATKINSON, R., MCBEATH, C., MEACHAM, D. Quality in distance education: ASPESA Forum 91. Bathurst, NSW.: Australian and South Pacific External Studies Association., 1991.

BINSARDI, A.; EKWULUGO, F. International marketing of British education: research on the students perception and the UK market penetration. Marketing Intelligence \& Planning, Vol. 21 No. 5, 2003.

cross ref

BUKOWITZ, W. R.; WILliAMS, R. L. Manual de gestão do conhecimento. Bookman, São Paulo, 2002. 
CARVALHO, A.V. Treinamento: princípios, métodos e técnicas. S. P.: Pioneira, 2001.

CARVALHO, M. J. S.; NEVADO, R. A.; MENEZES, C. S. Arquiteturas pedagógicas para educação a distância: Concepções e Suporte Telemático. 2004.

CASTElls, M. A sociedade em rede. Manual . São Paulo: Paz e Terra, 1999.

CASTElls, M. A Sociedade Em Rede - A Era da Informação: Economia, Sociedade e Cultura. São Paulo: Paz e Terra, v.1, 2002.

CHIAVENATO, I.. Administração nos novos tempos. $4^{\text {a }}$ ed. Campus, Rio de Janeiro, 1999.

COOPER, K. C. Effective competency modeling \& reporting. New York: Amacon, 2000.

CURY, M. V. Q. Modelo heurístico neuro -fuzzy para avaliação humanística de projetos de transporte urbano. Tese (Doutorado em Engenharia de Produção) - Universidade Federal do Rio de Janeiro, COPPE/UFRJ, 1999.

CURY, M. V. Q.; VEIGA, F. J. P. Método para avaliação do desempenho de rodovias concessionadas sob a ótica do usuário. 2004.

DAVENPORT, T.; PRUSAK, L. Working Knowledge: How Organizations Manage What They Know. Harvard Business School Press. Rio de Janeiro: Qualitymark, 1998.

FREEMAN, I. ; THOMAS, M. Consumerism in education: a comparison between Canada and the United Kingdom. The International Journal of Educational Management, Vol. 19 No. 2005.

GOMES, L.; MURPHY, J. The exploratory study of marketing international education online. The International Journal of Educational Management, Vol. 17 No. 3, 2003.

cross ref

GRAMIGNA, M. R. Modelo de competências e gestão de talentos. São Paulo: Makron Books, 2002.

ICDE. International Council for Distance Education . Disponível em: <http://.icde.org>. Acesso em: 21 abr. 2008.

KAYE, A. Computer-mediated communication in distance education. in Mason, R. and Kaye, A. (Eds), Communication, Computers and Distance Education, Mindweave, Pergamon, Oxford, 1989.

KAHANER, L Competitive Intelligence : from black ops to boardrooms - how business gather, analyze, and information to succed in the global maketplace. Ed. Simon \& Shuster. New York, USA, 1996.

KHAN, B. Managing E-Learning strategies: design, delivery, implementation and evaluation. George Washington University, Washington, DC, 2005.

cross ref

KING, R. What is higher education for? Strategic dilemmas for the twenty first century university. Quality Assurance in Education, Vol. 3 No. 4, 1995.

LAASER, W. Manual de criação e elaboração de materiais para educação a distância. Brasília: CEAD Universidade de Brasília, 1997.

LABAY, D. G.; COMM, C. L. A case study using gap analysis to assess distance learning versus traditional course delivery. The Journal of Educational Management, Vol. 17 No. 7, 2003.

LEIDECKER, J. K.; BRUNO, A.V. Identifying and using critical success factors. Long Range Planning, 1984.

LEVY, S. Six factors to consider when planning online distance learning programs in higher education. Disponível em: <http://www.e-mentor.edu.pl/>. Acesso em: 23 mar. 2007.

LITTO, F. M. ; FORMIGA, M. Educação a distância: o estado da arte. Associação Brasileira de Educação a Distância. Pearson Education do Brasil. São Paulo, 2008. 
LUZZI, D. A. O papel da educação a distância na mudança de paradigma educativo: da visão dicotômica ao continuum educativo. Tese de doutorado apresentada ao Programa de Pós-Graduação em Educação da Universidade de São Paulo - 2007.

MÂSIH, R. T. Um método para modelagem das competências individuais vinculadas à estratégia empresarial por meio do Balanced Scorecard. Tese de doutorado apresentada à Pós-Graduação do curso de Engenharia de Produção da Universidade Federal de Santa Catarina, 2005.

MIHHAILOVA, G. E-learning as internationalization strategy in higher education Lecturer's and student's perspective . Baltic Journal of Management Vol. 1 No. 3, 2006 pp. 270-284, 2006.

MILLER, A. I. Imagery and instuition in creative e scientific thinking: Albert Einstein Invention of the special theory of realativity, Creative People at. Work: Twelve Cognitive Case Studies. Oxford Unviersity Press, New York, 1989.

MINTZBERG, H. et al.. O processo da estratégia: conceitos, contextos e casos selecionados. Tradução Luciana de Oliveira da Rocha. 4ª edição. Bookman, 2006.

MOORE, M.; KEARSLEY,G. Educação a distância: uma visão integrada. Tradução de Roberto Galman. São Paulo: Thompson Learning, 2007.

MOORE, M. Theory of transactional distance, in Keegan, D. (Ed.), Theoretical Principles of Distance Education, Routledge, London,1993.

MORESI , E. A. D. Gestão da informação e do conhecimento. Editora UnB. Brasília-DF, 2001.

MORRISON, J. L. US higher education in transition. On the Horizon, Vol. 11 No. 1, 2003.

NONAKA, I. The Knowledge Creating Company, in: Harvard Business Review, November-December, 1991.

NONAKA, I.; TAKEUCHI, H. Criação do conhecimento na empresa: como as empresas japonesas geram a dinâmica da inovação. Campus, Rio de Janeiro, 1997.

PARRY, S. B. Just What is a Competency? (And why should you care?). Training, v. 35, n. 6, 1988.

PARRY, S. B. The quest for competencies. Training. Jul. 1996. Vol. 33. No. 07, 1996.

PETERS, O. Learning and teaching in distance education: pedagogical analysis and interpretations in an international perspectives. Open and Distance Learning Series. London: Kogan Page, 2001.

PORTAL DA ALLAMA IQBAL OPEN UNIVERSITY. Centros de Estudo. Disponível em: <http:Ilwww.aiou.edu.pk>. Acesso em 19 abr. 2008.

PORTAL DA ATHABASCA UNIVERSITY. Disponível em: <http:॥www.athabascau.ca>. Acesso em: 14 abr. 2008.

PROBST, G.; STEFFEN, R.; ROMHARDT, K. Gestão do conhecimento: os elementos construtivos do sucesso. Bookman. Porto Alegre-RS, 2002.

REISMAN S. ; DEAR, R. G. ; EDGE, D. (2001). Evolution of Web-based distance learning strategies. The International Journal of Educational Management. 15/5, 245-251, 2001.

cross ref

ROMISZOWSKI, A. The future of E-learning as an educational innovation: factors influencing project success and failure. Associação Brasileira de Educação a Distância. Revista Brasileira de Aprendizagem Aberta e a Distância, São Paulo, Setembro, 2003.

ROCKART, J. F. Chief executives define their own data needs. Harvard Business Review, 1979.

SADLER-SMITH, E.; DOWN, S.; LEAN, J. Modern learning methods: rhetoric and reality. U Personnel Review, Vol. 29 No. 4, 2000, pp. 474-490. 
SEUFERT, S.; SEUFERT, A. The Genius Approach: Building Learning Networks for Advanced Management Education. Proceedings of the 32nd Hawaiian International Conference on System Sciences, Hawaii., 1999.

Proceedings... Hawaii, 1999.

SEUFERT, S.; BACK, A.; HÄUSLER, M. E-Learning, Cookbook for Internet-based Learning, Smartbook, Zuerich, Switzerland, 2001.

STAIR, R. M.; REYNOLDS G. W. (colab.) Princípios de sistemas de informação: uma abordagem gerencial. Trad. Alexandre Melo de Oliveira. Rio de Janeiro: LTC, 2002.

THIEL, E. E. Proposta de modelo de implantação de um projeto de gestão do conhecimento com base em processos organizacionais. Dissertação (Mestrado em Engenharia de Produção) - Universidade Federal de Santa Catarina, 2002.

THOMPSON, A. A.; STRICKLAND, A. J. Planejamento estratégico: elaboração implementação e execução. Editora Pioneira, São Paulo, 2000.

THOMPSON, M. A. et al. The Role of Competencies in an Integrated HR Strategy. ACA Journal; Summer, 1996.

THURSTONE, L. L. (1927). A law of comparative judgment. Psychological Review, 1927.

TSINGHUA UNIVERSITY. Modern Distance Education. Disponível em: 〈http://www.sce.tsinghua.edu.cn〉. Acesso em: 15 abr. 2008.

UNITED STATES DISTANCE LEARNING ASSOCIATION - (USDLA), (2000), (Web page), URL <http:// www.usdla.org>. Acessoem: 20 set. 2007.

UNIVERSIDAD NACIONAL DE EDUACIÓN A DISTANCIA. Disponível em: <http://apliweb.uned.es>. Acesso em: 14 abr. 2008.

UNIVERSITAS TERBUKA. Disponível em: 〈http:॥www.ut.ac.id>. Acesso em: 16 de abr. 2008.

UNIVERSITY OF SOUTH AFRICA. Disponível em: <http:॥www.unisa.ac.za>. Acesso em: 16 abr. 2008.

UNIVERSITY OF THE AIR. Disponível em: <http:॥.u-air.ac.jp>. Acesso em: 15 abr. 2008.

VOLERY, T.; LORD, D. Critical success factors in online education. The International Journal of Educational Management 14/5 [2000] 216 223 \# MCB University Press [ISSN 0951-354X]. Disponível em: The current issue and full text archive of this journal is available at <http://www.emerald-library.com>. Acesso em 18/08/2008.

\section{Dados dos autores:}

\section{Nome completo: Edson Walmir Cazarini}

Filiação institucional: Escola de Engenharia de Produção

Departamento: Engenharia de Produção

Função ou cargo ocupado: Professor

Endereço completo para correspondência (bairro, cidade, estado, país e CEP): Av. Trabalhador São Carlense, 400 - CEP: 13566-590 - São Carlos/SP

Telefones para contato: (16) - 3373-8238

e-mail: cazarini@sc..usp.br

Nome completo: Selma Regina Martins Oliveira 
Filiação institucional: Escola de Engenharia de São Carlos

Departamento: Engenharia de Produção

Função ou cargo ocupado: Professora colaboradora

Endereço completo para correspondência (bairro, cidade, estado, país e CEP): Rua: Arlindo Gomes

Rodrigues, 1082 - Santa Mônica - Uberlândia - MG - CEP: 38406-231.

Telefones para contato: (16) 3373-8238

e-mail: selmaregina@webmail.uft.edu.br

Enviado em: 04/03/2011

Aprovado em:09/12/2011 